\title{
Maintenance of Dental Records and Forensic Odontology Awareness: A Survey of Croatian Dentists with Implications for Dental Education
}

\author{
Ivana Savić Pavičin ${ }^{1}\left(\mathbb{D}\right.$, Ana Jonjić ${ }^{2}$, Ivana Maretić ${ }^{3}$, Jelena Dumančić ${ }^{1,4, *(D)}$ and Ajla Zymber Çeshko ${ }^{5}$ \\ 1 Department of Dental Anthropology, School of Dental Medicine, University of Zagreb, 10000 Zagreb, Croatia; \\ savic@sfzg.hr \\ 2 School of Dental Medicine, University of Zagreb, 10000 Zagreb, Croatia; ana.jonjic94@gmail.com \\ 3 Private Dental Polyclinic Vinica, 42000 Varaždin, Croatia; s.mareticivana@gmail.com \\ 4 Department of Dental Medicine, University Hospital Centre Zagreb, 10000 Zagreb, Croatia \\ 5 School of Dentistry, FAMA College, 10000 Prishtina, Kosovo; ajlazymber1@icloud.com \\ * Correspondence: dumancic@sfzg.hr; Tel.: +385-1-4802-146
}

Citation: Savić Pavičin, I.; Jonjić, A.; Maretić, I.; Dumančić, J.; Zymber Çeshko, A. Maintenance of Dental Records and Forensic Odontology Awareness: A Survey of Croatian Dentists with Implications for Dental Education. Dent. J. 2021, 9, 37. https://doi.org/10.3390/dj9040037

Academic Editor: Hans S. Malmstrom

Received: 9 February 2021

Accepted: 22 March 2021

Published: 25 March 2021

Publisher's Note: MDPI stays neutral with regard to jurisdictional claims in published maps and institutional affiliations.

Copyright: (c) 2021 by the authors. Licensee MDPI, Basel, Switzerland. This article is an open access article distributed under the terms and conditions of the Creative Commons Attribution (CC BY) license (https:// creativecommons.org/licenses/by/ $4.0 /)$.

\begin{abstract}
Forensic odontology is the application of dentistry within the criminal justice system. Forensic expertise, including dental identification, mostly relies on dental records. We explored the practice of maintaining dental records among Croatian dentists, as well as their knowledge of legal regulations and the application of dental records in forensic odontology. In all, 145 dentists participated in an online survey. Questions covered general information on dentists, maintenance of dental records, and knowledge of legal requirements and forensic odontology. Overall, 70\% of dentists obtain and archive written informed consents, while $87 \%$ record dental status. Generally, non-carious dental lesions and developmental dental anomalies were not recorded. About $72 \%$ of dentists record filling material and surfaces. Only 32\% of dentists know the legal requirements for keeping records, whereas $21 \%$ have no knowledge of forensic odontology and its purpose. The survey revealed different practices in the maintenance of dental records, including significant flaws and lack of awareness of its forensic importance. This obvious need for additional education on proper maintenance of dental records could be met by including forensic odontology in compulsory undergraduate courses and postgraduate dental education. Establishing national and international standards in dental charting would comply with contemporary trends in health care and the requirements of forensic expertise.
\end{abstract}

Keywords: dental record; record keeping; documentation; forensic odontology; dental education; Croatia

\section{Introduction}

Forensic odontology is a branch of dentistry that applies dental science in order to provide evidence in the interest of the law [1]. It includes dental identification, bitemark analysis, age estimation, and expertise in civil litigation cases related to dental malpractice and injuries [2]. Besides dental identification, other forensic odontology methods can be utilized in personal identification, such as lip prints (cheiloscopy) and palatal rugae patterns (rugoscopy) [3,4]. Most of these procedures rely on dental documentation, which is a source regarding an individual's antemortem dental information. It consists of their dental record with a status chart, intraoral and extraoral X-rays, photographs, dental casts, medical history, and written consent [5]. Numerous qualitative and quantitative characteristics of teeth make dental identification a high-value forensic procedure. Its advantages are the ease of utilizing such resources as well as minor technological and financial requirements. Dental identification is especially useful in cases where teeth are the only remaining preserved parts of a human body: fires, mass graves, plane crashes, or natural disasters such as floods and avalanches [5-8]. However, for dental identification to be successful, dentists must 
conscientiously keep dental documentation on their patients. Additionally, the importance of maintaining and keeping dental records in terms of legal requirements should also be emphasized, where such records demonstrate the quality and thoroughness of dental care when presented in court proceedings and when providing forensic expertise [5]. Maintaining and keeping dental records are legal obligations for all dentists [9].

In Croatia, the use of dental identification began in the 1970s, when mass casualties occurred in two traffic accidents. Later, another significant development was during and after the Croatian War of Independence 1991-1995, when a need to identify victims from mass graves emerged [10].

The lack of data on the current practice of maintaining dental records has led us to investigate the thoroughness and comprehensiveness of practices in maintaining dental records, including knowledge and awareness among dentists of the legal importance and possibilities of using such records for forensic purposes.

\section{Materials and Methods}

This research was conducted using an online questionnaire (Google Forms) and titled "Questionnaire on Practices and Quality of Maintaining Dental Records in the Republic of Croatia and Possibility of its Use for Forensic Purposes". Prior to its use, it received approval from the Ethics Committee of the School of Dental Medicine, University of Zagreb. In 2019, the questionnaire was sent to 197 email addresses, available publicly or through social media. In all, 145 dentists participated in the survey, giving a response rate of $74 \%$.

The survey consisted of 40 questions with single, multiple choice, and open-ended questions.

Given below is an outline of the organization of the questions into five sections.

\subsection{General Information on Dentists}

The first group of questions was formulated to obtain information on gender, age, years of work experience, and the location of the respondent's dental practice. This included questions on the school of basic dental degree and type of employment covering options such as public dental service at a health center, private practice under contract with the Croatian Health Insurance Fund (CHIF), exclusively private practice, or working in a clinic or polyclinic.

\subsection{Data on Dental Documentation}

The questions focused on the practice of taking the general patient information such as gender, date of birth, contact number, and address, as well as the maiden name for female patients, names of other dentists the patient has visited, and name of their general practitioner.

Questions also covered recording medical history and entering dental status in the patient's records. This also included information on trauma, anomalies in tooth number, position and morphology, and developmental changes in dentitions. The issue of using abbreviations in documentation and treatment codes as stipulated by the CHIF was also addressed. The frequency of the routine use of $\mathrm{X}$-rays and photographs was also examined.

\subsection{Information on Dental Documentation Keeping}

Questions posed in this section addressed the format of dental documentation, including all relevant components and the duration of storing dental documentation as stipulated in the Dental Medicine Act of the Republic of Croatia [9]. A question was also asked as to what dentists considered a barrier to better management of dental documentation in their everyday work 


\subsection{Knowledge of Legal Aspects of Dental Practice}

Respondents were given the opportunity to answer questions on obtaining written consents, archiving them, and their knowledge of the right of patients to dispose of personal dental records.

\subsection{Awareness of Forensic Odontology}

This section enquired about the level of awareness among dentists and their acquired education in forensic odontology.

A statistical analysis was performed using IBM SPSS Statistics (Version 25.0. Armonk, NY, USA: IBM Corp.). A chi-square test was used to assess differences in categorical variables except in cases when there were less than 10 participants per cell, when Fisher's exact test was used. The statistical significance level was set at $p<0.05$.

\section{Results}

\subsection{General Information on Dentists}

The largest number of respondents belonged to the age group of 25 to 45 years, possessed 5 to 20 years of work experience, and were employed in a public health center, respectively. Most of the respondents were graduates of the School of Dental Medicine, University of Zagreb, and were employed in cities across Central Croatia. (Table 1).

Table 1. General information on dentists (number, percentage (\%)).

\begin{tabular}{|c|c|c|}
\hline Gender & $\begin{array}{c}\text { Female } \\
\text { Male }\end{array}$ & $\begin{array}{c}116(80.0) \\
29(20.0)\end{array}$ \\
\hline \multirow{2}{*}{ Age } & $25-45$ years & $102(70.3)$ \\
\hline & $45-65$ years & $43(29.7)$ \\
\hline \multirow{3}{*}{ Work experience } & $<5$ years & $33(22.8)$ \\
\hline & $5-20$ years & $78(53.8)$ \\
\hline & $20<$ years & $34(23.5)$ \\
\hline \multirow{4}{*}{ School of basic dental degree } & $\begin{array}{c}\text { School of Dental Medicine University } \\
\text { of Zagreb }\end{array}$ & $118(81.4)$ \\
\hline & $\begin{array}{c}\text { Study of Dental Medicine University } \\
\text { of Rijeka }\end{array}$ & $16(11.0)$ \\
\hline & Study of Dental Medicine University of Split & $7(4.8)$ \\
\hline & Other & $4(2.8)$ \\
\hline \multirow{4}{*}{ Practice location, region } & Central Croatia & $68(46.9)$ \\
\hline & Istria and Croatian Littoral & $18(12.4)$ \\
\hline & Slavonia & $23(15.9)$ \\
\hline & Dalmatia & $36(24.8)$ \\
\hline \multirow{4}{*}{ Type of employment } & Public health center & $49(33.8)$ \\
\hline & Private practice with $\mathrm{CHIF}{ }^{*}$ contract & $42(29.0)$ \\
\hline & Private practice & $31(21.4)$ \\
\hline & Clinic/polyclinic & $23(15.9)$ \\
\hline
\end{tabular}

${ }^{*}$ Croatian Health Insurance Fund.

\subsection{Data on Dental Documentation}

Statistical analysis shows that $86.9 \%$ of dentists record dental status at first visit, and this routine is more prevalent among dentists in health centers and private practices operating under a CHIF contract than those operating exclusively in private practices $(p<0.05)$. (Table 2). 
Table 2. Dental documentation: data items recorded/retained (number, percentage (\%)).

\begin{tabular}{|c|c|c|}
\hline \multicolumn{2}{|c|}{ Record patients' basic personal data } & $145(100.0)$ \\
\hline \multicolumn{2}{|c|}{$\begin{array}{l}\text { Record patients' additional personal details (maiden name, name of } \\
\text { general practitioner, name of another dentist) }\end{array}$} & $67(46.2)$ \\
\hline \multirow{2}{*}{ Medical history } & Record & $135(93.1)$ \\
\hline & Record and update with each visit & $93(64.1)$ \\
\hline \multirow{3}{*}{ Full dental status } & Record on first visit & $126(86.9)$ \\
\hline & Update with each visit & $45(31.0)$ \\
\hline & Update twice a year & $41(28.3)$ \\
\hline \multirow{9}{*}{$\begin{array}{l}\text { Record additional data } \\
\text { on dentition }\end{array}$} & Changes in dentitions & $80(55.2)$ \\
\hline & Trauma data & 119 (82.1) \\
\hline & Dental anomalies & (0.1) \\
\hline & Number & $87(60.4)$ \\
\hline & Position & $48(33.1)$ \\
\hline & Shape & $16(11.0)$ \\
\hline & Diastema & $19(13.1)$ \\
\hline & Non-carious lesions & $51(35.2)$ \\
\hline & Occlusion, Angle's classification & $29(20.0)$ \\
\hline \multirow{3}{*}{$\begin{array}{l}\text { Record details for } \\
\text { restorative treatment }\end{array}$} & Filling surface & $104(71.7)$ \\
\hline & Filling material & $104(71.7)$ \\
\hline & $\begin{array}{l}\text { Other (color, Black's classification, type } \\
\text { of preparation) }\end{array}$ & $87(60.0)$ \\
\hline \multirow{2}{*}{\multicolumn{2}{|c|}{$\begin{array}{l}\text { Use abbreviations/codes for recording treatment } \\
\text { Store past list of codes for treatment stipulated by the CHIF after they } \\
\text { have been changed }\end{array}$}} & $101(69.7)$ \\
\hline & & $43(29.7)$ \\
\hline \multirow{3}{*}{ Use of tooth coding } & FDI system & $104(71.7)$ \\
\hline & Palmer-Zsigmondy system & $28(19.3)$ \\
\hline & ADA Universal system & $20(13.8)$ \\
\hline \multirow{4}{*}{ Routinely take X-rays } & Orthopantomogram & $137(94.5)$ \\
\hline & Periapical radiograph & $101(69.7)$ \\
\hline & Bitewing radiograph & $45(31.0)$ \\
\hline & Do not routinely take X-rays & $5(3.4)$ \\
\hline \multicolumn{2}{|c|}{ Take intraoral or extraoral (facial) photographs } & $89(61.4)$ \\
\hline
\end{tabular}

The practice of updating dental status data is less common for male than female dentists $(p<0.05)$. Dentists in Istria collect significantly more additional data on patients compared with dentists in Dalmatia $(p<0.05)$. In collecting additional data on patients, dentists employed in clinics or polyclinics are more up to date than employees in private practices $(p<0.05)$. When recording details for restorative treatment, such as the color of a material, Black's classification, or the type of preparation, female dentists recorded more details than their male counterparts $(p<0.05)$. The analysis also shows that dentists employed in health centers more often keep old codes for treatment as stipulated by the CHIF than doctors employed in private practices operating under a CHIF contract $(p<0.05)$.

Extraoral and intraoral photographs are more often used by doctors in Central Croatia and Istria than by doctors in Slavonia $(p<0.05)$. Also, photos are used more often in private surgeries, whether operating under a CHIF contract or not, and in clinics, than in health centers $(p<0.05)$.

\subsection{Data on Dental Documentation Keeping}

The largest number of respondents answered that they keep dental records for a period of five to ten years (33\%) while a further $45 \%$ keep such records for even longer.

The analysis shows that documentation was kept longer by doctors in Istria and the Croatian Littoral (northern coastal region) than in Dalmatia (southern coastal region) 
and Slavonia $(p<0.05)$. The same practice is observed in doctors employed in clinics and polyclinics compared with dentists employed in health centers or private practices operating under a CHIF contract $(p<0.05)$. Statistical analysis shows that dentists in health centers kept $\mathrm{X}$-rays for a significantly shorter period (less than five years) compared with employees in private practices operating under a CHIF contract $(p<0.05)$. On the other hand, it is evident that doctors in private surgeries, regardless of whether operating under a CHIF contract or not, keep X-rays for significantly longer (more than 20 years) compared with those in health centers $(p<0.05)$. (Table 3$)$.

Table 3. Practice and duration of dental documentation keeping, and barriers to good practice (number, percentage $(\%)$ ).

\begin{tabular}{ccc}
\hline \multirow{2}{*}{ Format of dental records } & Digital form & $135(93.1)$ \\
& Digital form with backup & $99(68.3)$ \\
& Paper form & $73(50.3)$ \\
\hline \multirow{2}{*}{ X-ray format } & Analog & $63(43.4)$ \\
& Digital & $137(94.5)$ \\
\hline \multirow{2}{*}{ Duration of X-ray keeping } & $<5$ years & $18(12.4)$ \\
& $5-10$ years & $54(37.2)$ \\
& $11-15$ years & $34(23.4)$ \\
Other documentation keeping & $16-20$ years & $9(6.2)$ \\
up to 10 years & $>20$ years & $30(20.7)$ \\
\hline \multirow{2}{*}{ Barriers to good practice of } & Dental casts & $137(94.5)$ \\
record keeping & Temporary works & $141(97.2)$ \\
& Implant serial number & $88(60.7)$ \\
\hline & Lack of time & $110(75.9)$ \\
& Lack of education & $43(29.7)$ \\
& Do not consider it important & $51(35.2)$ \\
\hline
\end{tabular}

\subsection{Knowledge of Legal Aspects of Dental Practice}

In all, $69 \%$ of dentists seek written consents prior to treatment, with a significantly larger number in Istria than those in Dalmatia $(p<0.05)$. Depending on the type of dental practice, the analysis showed that doctors employed in clinics and polyclinics are more likely to obtain written consents than doctors employed in health centers and private practices $(p<0.05)$. (Table 4$)$.

Table 4. Knowledge of legal aspects of dental practice (number, percentage (\%)).

\begin{tabular}{ccc}
\hline Know the law on record retention for 10 years & $47(32.4)$ \\
\hline \multicolumn{2}{c}{ Obtain written consent before treatment } & $100(69.0)$ \\
\hline \multicolumn{2}{c}{ Retain informed consent } & $102(70.3)$ \\
\hline \multirow{2}{*}{$\begin{array}{cc}\text { Consider the patient's rights } \\
\text { in access to information }\end{array}$} & Right to the original records & $33(22.8)$ \\
& Right to a copy of records & No rights \\
\hline
\end{tabular}

\subsection{Awareness of Forensic Odontology}

Respondents who obtained their degree in dentistry outside of Croatia more often answered that they have no education or training in forensic odontology $(p<0.05)$. (Table 5). 
Table 5. Awareness of forensic odontology (number, percentage (\%)).

\begin{tabular}{ccc}
\hline & Identification of the deceased in & $138(95.2)$ \\
Recognize the scope of & unidentified cases & \\
forensic odontology in: & Identification of the perpetrator by & $109(75.2)$ \\
& bitemark analysis & Other legal proceedings \\
& Undergraduate study & $97(66.9)$ \\
\hline Familiarity with forensic & Specialist study & $104(72.2)$ \\
odontology gained in: & Professional continuing education & $5(3.4)$ \\
& Doctoral study & $19(13.1)$ \\
& No knowledge & $32(8.3)$ \\
\hline
\end{tabular}

\section{Discussion}

The total number of collected responses to the questionnaire was 145 , equivalent to a response rate of $74 \%$. Accordingly, the survey sampled $2.86 \%$ of the total number of currently active dentists in the Republic of Croatia, according to data from the Croatian Dental Chamber [11]. Although it is a low proportion of the total target population, the number is consistent with responses in similar studies $[1,12,13]$. Our study is the first study on the manner and quality (suitability) of maintaining dental records in the Republic of Croatia. Dentists from all parts of Croatia participated in the survey, with the highest response coming from Central Croatia, followed by Dalmatia. This is due to the larger population of cities in those areas, especially Zagreb as the Croatian capital and Split. The largest number of respondents coming from the 25 to 45 age group can be explained by the higher digital literacy of the younger generation of dentists.

Table 6 lists the current legal requirements for dental documentation maintenance in Croatia. Based on the results obtained in this study, it is evident that Croatian dentists keep dental records in line with statutory requirements and record basic patient data, such as gender, date of birth, address, and contact phone number. About $46 \%$ of respondents regularly entered additional data, which can be useful in forensic procedures. This was the case significantly more often for dentists in Istria and the Croatian Littoral as well as those working in clinics and polyclinics. This may be due to greater development of dental tourism in Istria and the Littoral, where foreign patients are treated [14], and possibly a greater awareness among dentists of the need to establish protective measures against potential lawsuits.

Dental charting, handwritten or electronic, should provide an up-to-date insight into the status of a patient's dentition, i.e., the number of existing natural teeth, detected caries lesions, fixed or mobile prosthetic works, fillings, and extractions. During a patient's first visit, dental status is taken by $87 \%$ of respondents, more often dentists working in health centers and private practices under a CHIF contract, compared with exclusively private practices $(p<0.05)$. A possible reason for this may be the fact that patients visit public or private surgeries operating under a CHIF contract over a longer period of time, and also when requiring conservative treatment, which is mainly covered by the CHIF, whereas patients visit private dental practice only for specific treatment or procedures, which are usually not covered by the CHIF. The second reason is that the CHIF supervises and controls the work of contracted practices. 
Table 6. Legal requirements for dental documentation maintenance in Croatia.

\begin{tabular}{|c|c|}
\hline Requirement & Law/Regulation \\
\hline $\begin{array}{l}\text { Patients' basic personal data to be registered in } \\
\text { e-charts }\end{array}$ & $\begin{array}{l}\text { Regulation on maintenance of electronic } \\
\text { personal health record }\end{array}$ \\
\hline $\begin{array}{l}\text { Dental documentation must be accurate, } \\
\text { detailed, and dated, covering patient's status } \\
\text { and treatment }\end{array}$ & Law on dental medicine \\
\hline $\begin{array}{l}\text { Documentation in electronic form must be } \\
\text { protected from changes, unauthorised use, and } \\
\text { early destruction }\end{array}$ & Law on dental medicine \\
\hline $\begin{array}{l}\text { Dental documentation consists of dental record } \\
\text { with status chart, medical/dental history, } \\
\text { radiographs, and photographs }\end{array}$ & Law on dental medicine \\
\hline $\begin{array}{l}\text { Obligation to allow patient to access } \\
\text { documentation }\end{array}$ & Law on dental medicine \\
\hline Obligation of record retention for 10 years & Law on dental medicine \\
\hline $\begin{array}{l}\text { Patient's right to informed consent } \\
\text { Content of informed consent } \\
\text { form/refusal form }\end{array}$ & $\begin{array}{l}\text { Law on patients' rights } \\
\text { Law on informed consent/refusal form }\end{array}$ \\
\hline
\end{tabular}

Dental status changes are entered in status charts by $31 \%$ of dentists, with $28 \%$ of them doing so twice a year, which may correspond to the term "each visit", as regular dental checkups are usually performed every six months. Therefore, almost $60 \%$ of dentists regularly update dental charts. Although the proportion of dentists who do not record a detailed status at the first patient visit is small (13\%), noting that approximately $40 \%$ do not update such statuses regularly, these data are somewhat worrying. In terms of children's oral health care, regularly recording changes in dentition is important, and was performed by $55 \%$ of dentists in our study. In forensic analysis, developmental changes in dentition enable estimation of dental age. As for children, there can be only a small number of restorations, if any, and dental age estimation may be crucial for individual identification. An example of such a case is the plane crash over Vrbovec (Croatia), which happened in 1976, where dental age estimation provided supportive evidence for the identification of eight child victims of the accident [10].

Dental anomalies are also important for dental identification because they are relatively rare and provide a unique characteristic to dentition without caries and dental procedures. As the incidence of caries decreases in highly developed countries, the importance of anomalies for dental identification will increase even more. This study shows that dentists rarely recorded dental anomalies except for tooth number anomalies, which were recorded by $60 \%$ of respondents (Table 2). Also, only $35 \%$ of respondents recorded noncarious dental lesions such as erosion, attrition, and abrasion.

After performing a restorative procedure, data on materials and methods should be entered in the progress notes in the patient record. The majority of surveyed dentists, about $70 \%$, use abbreviations or codes for recording treatment, while only $30 \%$ keep old lists of abbreviations after changes. This is a worrying fact because analysis of premortem dental data requires legible, clear, and easily accessible information [1,15]. Statistical analysis has shown that keeping old codes was more often done by dentists who practice in health centers. The reason for this is the fact that dentists in health centers use codes for the purpose of charging of fees to the CHIF, while in private practices payments are made by patients.

For tooth notation, $72 \%$ of dentists most often use the FDI tooth numbering system, while the Palmer-Zsigmondy system is more commonly used by respondents who graduated from the University of Split. 
The most common choice of radiological image for a routine check-up was an orthopantomogram (95\%). Five respondents (3\%) answered that they do not routinely take $X$-rays. Although this is small in number, it is a warning which indicates insufficient education on the importance of X-rays in diagnosing various conditions otherwise undetectable in clinical examinations, as well as in planning therapy and monitoring development in children.

Though not obligatory except in orthodontics and oral rehabilitation, intraoral and extraoral photographs are an excellent complementary record for dental documentation and have great importance in forensics. According to the survey results, photographs were used by $61 \%$ of respondents. We consider this a good result, given that it is optional in dental documentation. In modern private practices, dental photography is increasingly used in documenting the initial status of patients and therapy planning.

Most of the respondents (93\%) keep documentation in digital form, with $73 \%$ using storage on additional media as protection against alteration, premature destruction, or unauthorized use, as required by law [9]. The duration of archiving $X$-rays was most often 5 to 10 years (37\%), with a further $40 \%$ of respondents archiving $X$-rays for even longer. Comparing antemortem and postmortem radiographs may be crucial for dental identification. Even old radiographs can be used to compare tooth morphology and surrounding bone structures.

More than $94 \%$ of respondents keep dental casts and temporary replacements in dental documentation. Serial numbers of implants are recorded by $61 \%$ of respondents. Statistical analysis showed that dentists working in private practices keep implant serial numbers for significantly longer than dentists in health centers. The reason may be that most implants are used in private surgeries since the CHIF does not cover the costs of implant treatment. Another explanation may be the high cost of implants and possible complaints.

In our study, when asked about barriers to better record keeping, $76 \%$ of respondents said it was a lack of time, while $30 \%$ indicated a lack of education.

The obligation to keep dental records in Croatia is regulated by the Dental Medicine Act [9]. Only 57 respondents (39\%) answered that they know about the period that the law prescribes for archiving documentation, and only $47(32 \%)$ gave the correct answer of 10 years. Most respondents acquired training in forensic dentistry in their undergraduate studies $(72 \%)$, with more than a fifth of respondents stating that they have no knowledge about forensic odontology and its purpose. Statistical analysis shows that most dentists lacking knowledge of forensic odontology studied outside Croatia (abroad).

Australian dentists record basic personal data of patients in $82 \%$ of cases, with only $29 \%$ taking additional personal details, which is less often than Croatian dentists [1]. The study by Thampan et al. on a sample of 543 dentists from southern India showed that almost all respondents (97\%) record basic patient data; however, the recording of additional data was not investigated [16]. Survey results of American dentists showed similar results to their Croatian counterparts regarding updating information in dental documentation [17]. Most dentists agree on the importance of updating information and cite time constraints as a major obstacle.

Two Indian studies have shown that $89 \%$ of dentists in India record dental anomalies and anatomical variations such as the torus mandibularis [16,18], significantly more so than in Croatia. Our results are similar to those in a survey on Australian dentists [1], who keep good records of personal patient data and details of restorative procedures, but somewhat less so when it comes to dental anomalies.

In terms of using abbreviations for recording treatment, our results are comparable to those from Indian dentists, with $67 \%$ of dentists using abbreviations or codes [18]. Abbreviations are kept by as much as $64 \%$ of Indian dentists as opposed to $30 \%$ of Croatian dentists.

In a paper on dental investigation in an air disaster, Ligthelm emphasized the need for international standardization of abbreviations and the maintenance of dental records [10]. This problem is particularly significant in accident investigations involving victims from other countries, as was the case in Thailand after the 2004 tsunami [19]. This is increasingly 
the case due to the current increasing trend of international migration. In 2019, it was estimated that there are 272 million people living in countries other than their country of birth, which is $3.5 \%$ of the world's population [20]. With approx. 82 million migrants, Europe ranks second place, after Asia which has 84 million migrants. Thousands of migrants die while trying to reach Europe, becoming "missing migrants". The Mediterranean Sea is where the highest number of known deaths during migration occur, i.e., 17,919 deaths over a span of five years (2014-2018). These trends are increasing the demand for forensic odontology expertise in human identification and age estimation for the purposes of preventing human rights violations [21]. Croatia, an EU member state, is a transit country for migrants that illegally cross EU borders while heading to Western Europe, and at the same time a country of origin for economic migrants who settle in Western European countries. Thus, legible dental documentation of Croatian citizens may be requested by dentists and forensic odontologists in other European countries, while Croatian forensic odontology experts may encounter challenges in obtaining dental records of migrants from Africa and Asia.

Poor record keeping can be expected in less developed countries [16,18,22-24], but research shows such insufficiencies even in highly developed countries such as the United Kingdom, where as many as $44 \%$ inaccurate dental records were found [25]. Research in Sudan has shown that dental students keep dental records more accurately than dentists in private clinics [23].

The situation is similar with archiving dental records, which is regulated by law in developed countries. It may come as a surprise that the legal obligation to maintain such documentation was introduced in Belgium as late as in 2004, and prior to that, it was only deontological and ethical codes that imposed the obligation on dentists to do so [12]. Dentists in India often do not keep records of treatments performed (22\%), and if they keep X-rays, it is only for a few months up to a maximum of three years [18]. In Australia and New Zealand, as many as $85 \%$ of dentists keep X-rays taken by other dentists, and $63 \%$ retain even faulty X-rays [1]. Both Australian and Indian dentists are exceptionally consistent in recording implant serial numbers $(70 \%)[1,18]$ and, to a lesser extent, Croatian dentists in our research $(61 \%)$.

American dentists recognize the importance of adequate record keeping and archiving but, due to the lack of guidelines for updating patient records, they spend more time in other aspects of dental practice [17]. Perceived barriers to making accurate and complete dental records by Australian dentists are increased workloads in practice, time constraints, insufficient space for archives, lack of record quality check personnel, as well as lack of experience and education [1]. In our research, only a third of the dentists were familiar with the legal requirement of retaining documentation, and a fifth of the dentists had no knowledge of forensic dentistry and the possible use of dental documentation in forensic procedures.

In Croatia, forensic odontology was introduced as a mandatory course in undergraduate programs in 1997, with the establishment of the Chair of Forensic Dentistry at the School of Dental Medicine, University of Zagreb. It was later introduced in postgraduate programs and professional continuing education. Throughout the course, participants are introduced to the legal obligations of record keeping (informed consent, diagnosis, treatment plan, recording treatment) and the importance and application of documentation in dental identification and use in forensic expertise and litigation related to negligence, malpractice, and the qualification of orofacial injury. Since 2015, the harmonization of the study curriculum with recommendations of the Association for Dental Education in Europe has led to forensic odontology becoming an elective course in undergraduate programs. This has resulted in only some students enrolling onto the course, which is certainly a step backwards.

The International Organization for Forensic Odonto-Stomatology (IOFOS) investigated undergraduate education in forensic odontology and found that a specific teaching course in forensic odontology is neither mandatory nor elective in most undergraduate programs [26]. At the same time, the profile and competences for the graduating Euro- 
pean dentist include the Professionalism domain, composed of ethics, regulation, and professional behavior [27], which are covered in a basic forensic odontology course.

\section{Conclusions}

The results of this research show that Croatian dentists keep and store detailed dental documentation to a great extent; however, there are some insufficiencies in recording dental anomalies and non-carious lesions, as well as omissions in taking and updating dental status, omissions in the use of codes, and inconsistencies in recording fillings, as well as insufficient knowledge of legally required conditions for archiving records. The proper maintenance of dental documentation is become increasingly important due to the development of dental tourism, bringing a large influx of patients from foreign countries. Migration is also causing an increasing demand for forensic odontology expertise, requiring assessments of dental documentation from foreign countries, if available. There is evidently a need for additional education and raising awareness on the importance of properly maintaining dental records. This new direction is necessary not only to facilitate identification of unidentified bodies or bitemark perpetrators, but also to protect dentists from possible lawsuits and litigation. Our research data also indicate the need to adopt a national and international standard for keeping detailed and legible documentation that meets contemporary trends in health care and the requirements of forensic procedures.

Including forensic odontology in compulsory undergraduate courses as well as postgraduate and continuing professional education would equip dentists with knowledge and awareness of the importance and possible application of dental documentation. At the same time, it would allow dentists to achieve and maintain competences in the domain of professionalism. We expect the IOFOS to take further steps in advising authorities to include a basic course of forensic odontology in the undergraduate dental curriculum to meet these goals. Also, dental chambers should be advised to impose a continuing education course on the legal requirements for dental practice as a prerequisite for renewal of the license.

Author Contributions: Conceptualization, I.S.P.; methodology, I.S.P., A.J. and I.M.; investigation, I.S.P., A.J. and I.M.; formal analysis, I.S.P. and J.D.; writing-original draft preparation, A.J., I.M., J.D. and A.Z.Ç.; writing—review and editing, I.S.P. and J.D.; visualization, A.J. and I.M.; supervision, I.S.P. All authors have read and agreed to the published version of the manuscript.

Funding: This research received no external funding.

Institutional Review Board Statement: The study was approved by the Ethics Committee of the School of Dental Medicine, University of Zagreb, on 18 February 2019 (approval number: 05-PA-30IV-2/2019).

Informed Consent Statement: This research was conducted using an online questionnaire (Google Form). An invitation letter with a link to a questionnaire was sent to email addresses, available publicly or through social media. Only subjects willing to participate accessed and filled in the offered questionnaire anonymously.

Conflicts of Interest: The authors declare no conflict of interest.

\section{References}

1. Al-Azri, A.R.; Harford, J.; James, H. Awareness of forensic odontology among dentists in Australia: Are they keeping forensically valuable dental records? Aust. Dent. J. 2015, 61, 102-108. [CrossRef] [PubMed]

2. Brkić, H.; Lessig, R.; da Silva, R.H.A.; Pinchi, V.; Thevissen, P. (Eds.) Textbook of Forensic Odonto-Stomatology by IOFOS; Naklada Slap: Jastrebarsko, Croatia, 2021; 412p.

3. Bernardi, S.; Bianchi, S.; Continenza, M.A.; Pinchi, V.; Macchiarelli, G. Morphological study of the labial grooves' pattern in an Italian population. Aust. J. Forensic Sci. 2018, 52, 490-499. [CrossRef]

4. Chowdhry, A.; Kapoor, P. Cheiloscopy and Rugoscopy. In Textbook of Forensic Odonto-Stomatology by IOFOS; Brkić, H., Lessig, R., da Silva, R.H.A., Pinchi, V., Thevissen, P., Eds.; Naklada Slap: Jastrebarsko, Croatia, 2021; pp. 235-248.

5. Blažić-Potočki, Z.; Brkić, H.; Jerolimov, V.; Macan, D.; Valentić-Peruzović, M.; Varga, S.; Vojvodić, D. Vještačenje u Stomatologiji; Stomatološki Fakultet Sveučilišta u Zagrebu i Akademija Medicinskih Znanosti Hrvatske: Zagreb, Croatia, 2005; 107p. 
6. Hinchliffe, J. Forensic odontology, part 2. Major disasters. Br. Dent. J. 2011, 210, 269-274. [CrossRef] [PubMed]

7. Brkić, H.; Petrovečki, V.; Gusić, S. Dental Identification of the Carbonized Body: Case Review. Acta Stomatol. Croat. 2002, $36,119-125$.

8. Agrawal, N.K.; Dahal, S.; Wasti, H.; Soon, A. Application of Ultraviolet Light in Dental Identification of Avalanche Vic-tims. J. Nepal. Health Res. Counc. 2017, 15, 193-196. [CrossRef] [PubMed]

9. Zakon o Dentalnoj Medicini. Zakon.hr. Available online: https://www.zakon.hr/z/406/Zakon-o-dentalnoj-medicini (accessed on 2 May 2019).

10. Dumančić, J.; Kaić, Z.; Njemirovskij, V.; Brkić, H.; Zečević, D. Dental Identification after Two Mass Disasters in Croatia. Croat. Med. J. 2001, 42, 657-662. [PubMed]

11. Croatian Dental Chamber. Strategija Razvoja Dentalne Medicine 2017-2025. 2018. Available online: http://www.hkdm.hr/pic_ news / files/pdf/2019/strategija-dent-medicine-2017-2025.pdf (accessed on 2 May 2019).

12. Dierickx, A.; Seyler, M.; De Valck, E.; Wijffels, J.; Willems, G. Dental records: A Belgium study. J. Forensic Odonto Stomatol. 2006, 24, 22-31.

13. Gambhir, R.S.; Singh, G.; Talwar, P.S.; Gambhir, J.; Munjal, V. Knowledge and awareness of forensic odontology among dentists in India: A systematic review. J. Forensic Dent. Sci. 2016, 8, 2-6. [CrossRef] [PubMed]

14. Karahasanović, V. Dental Tourism Marketing in Istrian County. Graduation Thesis, Juraj Dobrila University of Pula, Pula, Croatia, 25 September 2017. Available online: https:/ / urn.nsk.hr/urn:nbn:hr:137:185351 (accessed on 1 May 2019).

15. Charangowda, B. Dental records: An overview. J. Forensic Dent. Sci. 2010, 2, 5-10. [CrossRef] [PubMed]

16. Thampan, N.; Janani, R.; Ramya, R.; Bharanidharan, R.; Kumar, A.; Rajkumar, K. Antemortem dental records versus individual identification. J. Forensic. Dent. Sci. 2018, 10, 158-163. [CrossRef] [PubMed]

17. Tokede, O.; Ramoni, R.B.; Patton, M.; Da Silva, J.D.; Kalenderian, E. Clinical documentation of dental care in an era of electronic health record use. J. Evid. Based Dent. Pract. 2016, 16, 154-160. [CrossRef] [PubMed]

18. Sarode, G.S.; Sarode, S.C.; Choudhary, S.; Patil, S.; Anand, R.; Vyas, H. Dental records of forensic odontological importance: Maintenance pattern among dental practitioners of Pune city. J. Forensic Dent. Sci. 2017, 9, 48. [PubMed]

19. Schuller-Götzburg, P. Dental Identification of Tsunami Victims in Phuket, Thailand. Acta Stomatol. Croat. 2007, 41, $295-305$.

20. International Organisation of Migration. World Migration Report. 2020. Available online: https://publications.iom.int/system/ files/pdf/wmr_2020.pdf (accessed on 10 January 2021).

21. Nuzzolese, E. Missing people, migrants, identification and human rights. J. Forensic Odonto Stomatol. 2012, 30, 47-59.

22. Wadhwani, S.; Shetty, P.; Sreelatha, S. Maintenance of antemortem dental records in private dental clinics: Knowledge, attitude, and practice among the practitioners of Mangalore and surrounding areas. J. Forensic Dent. Sci. 2017, 9, 78-82. [CrossRef] [PubMed]

23. Waleed, P.; Baba, F.; Alsulami, S.; Tarakji, B. Importance of Dental Records in Forensic Dental Identification. Acta Inform. Med. 2015, 23, 49-52. [CrossRef] [PubMed]

24. Preethi, S.; Einstein, A.; Sivapathasundharam, B. Awareness of forensic odontology among dental practitioners in Chennai: A knowledge, attitude, practice study. J. Forensic Dent. Sci. 2011, 3, 63-66. [CrossRef] [PubMed]

25. Brown, N.L.; El Jephcote, V.; Morrison, J.N.; Sutton, J.E. Inaccurate dental charting in an audit of 1128 general dental practice records. Dent. Updat. 2017, 44, 254-260. [CrossRef] [PubMed]

26. Pinchi, V. Education and Qualification in Forensic Odontology. In Textbook of Forensic Odonto-Stomatology by IOFOS; Brkić, H., Lessig, R., da Silva, R.H.A., Pinchi, V., Thevissen, P., Eds.; Naklada Slap: Jastrebarsko, Croatia, 2021; pp. 387-406.

27. Field, J.C.; Cowpe, J.G.; Walmsley, A.D. The Graduating European Dentist: A New Undergraduate Curriculum Frame-work. Eur. J. Dent. Educ. 2017, 21 (Suppl. 1), 2-10. [CrossRef] 